\title{
THE IMPACT OF EMISSIONS FROM A LARGE COAL-FIRED POWER PLANT ON NEARBY COMMUNITIES IN THE HADERA REGION, ISRAEL
}

\author{
NURIT SHAHAM-WALDMANN ${ }^{1}$, DANNY MOSHE $^{2}$, NIR SAHAR $^{1}$ \& ALAN GERTLER ${ }^{3}$ \\ ${ }^{1}$ Cities Association for Environmental Protection, Sharon-Carmel, Israel \\ ${ }^{2}$ GreenVision Systems, Ltd., Tel Aviv, Israel \\ ${ }^{3}$ Desert Research Institute, Reno, Nevada, USA
}

\begin{abstract}
The Orot Rabin power plant is a 2,590 MW coal-fired power plant located along the Mediterranean coast north of Tel Aviv. Close by to the east is the city of Hadera. Due to the predominant east-west wind patterns, both Hadera and the nearby communities may be impacted by stack emissions from the power plant. In addition, on-site storage of coal and coal residue can be a source of fugitive PM emissions. To determine the sources contributing to elevated $\mathrm{PM}_{10}$ levels in the region, a source apportionment study was performed at two locations (Hephziba and Pardes-Channa) during August/October 2017. We applied a microscopic chemical imaging (MCI) methodology based on particle fluorescence to determine PM source contributions in near-real time (GreenVision Systems, Ltd., Tel Aviv, "GVS"). For the Hephziba monitoring site, located closest to the power plant and adjacent to a major highway, the major emissions sources were mobile sources $(29.8 \%)$ and coal power plant emissions (29.1\%). In addition, fugitive coal and coal residue were estimated to contribute $11.5 \%$ of the observed $\mathrm{PM}_{10}$. At the Pardes-Channa site, located further inland and in a more residential area, contributors included mobile sources (38.6\%), coal power plant emissions (19.3\%), and fugitive coal and coal residue $(2.7 \%)$. These results indicate the significant impact of the power plant on observed $\mathrm{PM}_{10}$ in the region, with the nearby site also experiencing a major contribution from fugitive emissions from the facility.
\end{abstract}

keywords: PM10, source apportionment, air pollution, fugitive emissions.

\section{INTRODUCTION}

The city of Hadera is a major municipality $(2016$ population 91,707$)$ located north of the Tel Aviv metropolitan region in Israel. It is also adjacent to Caesarea, the third most popular tourist area in country. Located near the Mediterranean coast, Hadera is east of the Orot Rabin power plant, with the four large stacks from the 2590 MW coal-fired power station dominating the horizon. Previous environmental studies have observed elevated levels of pollutants inland from the plant, which are transported as far away as northern Jordan (Asaf et al. [1]). The nearby presence of the power station has raised questions regarding its impact on air quality in Hadera. The prevailing winds tend to transport the emissions along an eastwest axis and so there is a high likelihood of impact on Hadera and the nearby communities. In mid-2017 the local air quality control district (Cities Association for Environmental Protection, CAEP) received complaints about fugitive emissions from the coal power station depositing on the community of Hephziba, which is located a few kilometers due east of the facility. To address the issue of the impact of the Orot Rabin power plant on the local area, we conducted a PM source apportionment study to determine the relative contributions of various sources to the observed $\mathrm{PM}_{10}$ concentrations during the September/October 2017. 


\section{DESCRIPTION OF SAMPLING LOCATIONS}

As part of this study, we chose two monitoring locations along the east-west axis extending from the power station inland towards Hadera (Fig. 1). These included Hephziba, the small community that had voiced concerns about fugitive emissions impacts and Pardes-Channa, a location further inland with a monitoring station operated by CAEP. The sites were chosen to assess the impact of stack emissions from the power station and the change in the relative source contributions from any fugitive emissions.

For the Hephziba location, samples were collected on Teflon filters using a minivol sampler fitted with a size-selective $\mathrm{PM}_{10}$ inlet operating at a flow rate of $5 \mathrm{lpm}$. The sampler was located on the second-floor porch of a residence facing west (the direction of the power station). Samples were collected during the period of August 30 to October 16, 2017. Collection times varied from 12 to 24 hours, with the 12-hour samples ranging from midnight to noon and noon to midnight. The reason for the inconsistencies in sampling times was the restriction on changing filters during the Jewish Sabbath and High Holidays (Rosh Hashanah and Yom Kippur). At Pardes-Channa, samples were collected on a continuous Teflon strip fitted to an FRM (Federal Reference Method) volume sampling system of $16.7 \mathrm{lpm}$ and a $\mathrm{PM}_{10}$ inlet. The sampling system was located at an air quality monitoring station operated by CAEP. Samples were collected continuously during the period September 13 to October 14 for 12-hour intervals (midnight to noon and noon to midnight). Since the sampling system operated automatically, there was no restriction on the sampling periods and so a continuous record of 12-hour samples was collected at this location.

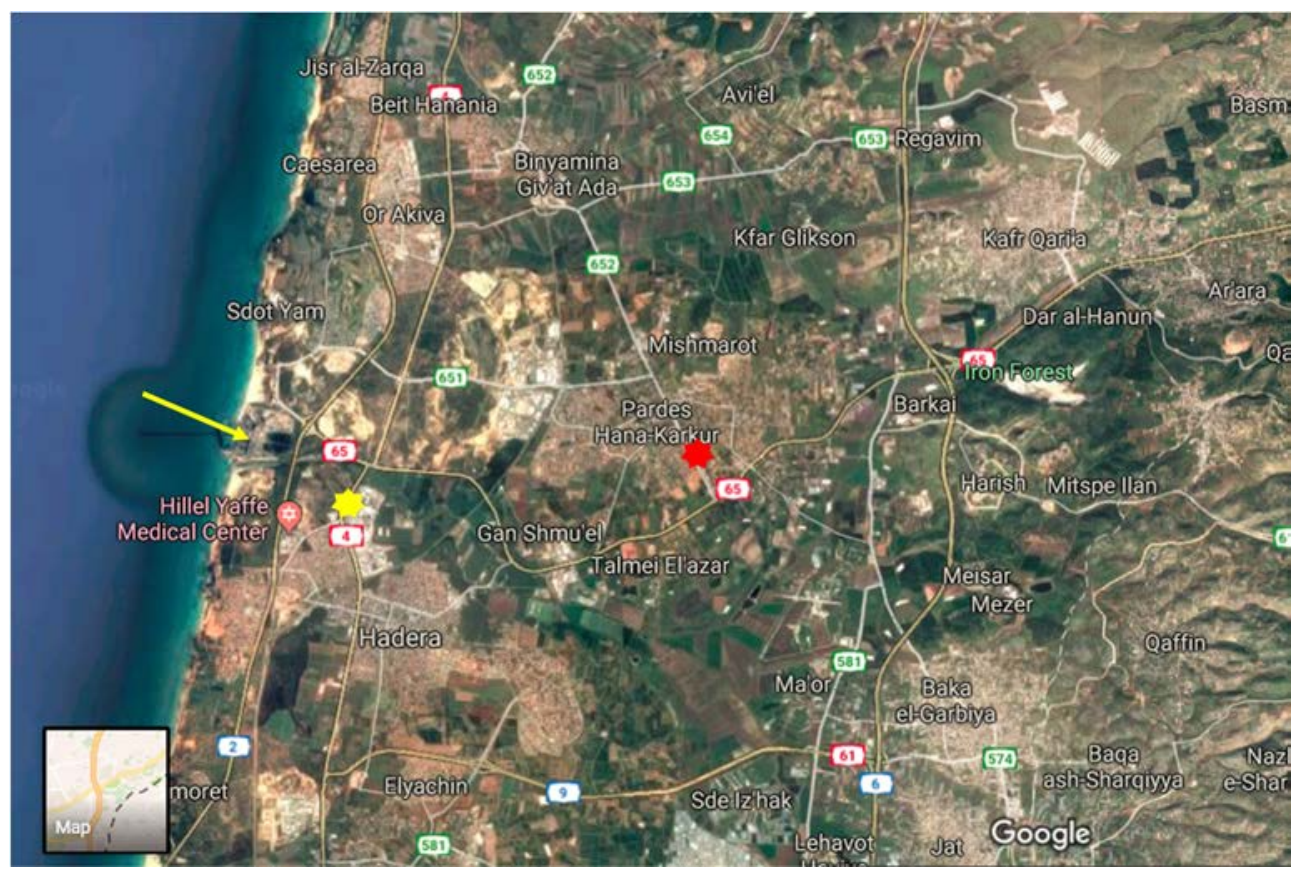

Figure 1: Locations of the Hephziba (yellow star) and Pardes-Channa (red star) monitoring locations. The power station is located on the coast, across the highway from Hephziba (yellow arrow). 


\section{SOURCE APPORTIONMENT METHODOLOGY}

Samples were analyzed using a microscopic chemical imaging (MCI) approach and GVS system, previously described by Gertler et al. [2]. This methodology employs chemical imaging coupled with adaptive learning algorithms to identify chemical species that are present on the collected particles. Briefly, the instrument scans the collected particles and records the particle-by-particle spectra for the wavelength region of 390-1000 nm using an interferometer based imaging Fourier spectrometer coupled to a fluorescence microscope with UV optics and an interferometer with wavelength accuracy of $2 \mathrm{~nm}$. The image is digitized and pixel-by-pixel spectral information is collected (Fig. 2). Particle size and morphology information is also recorded. The instrument software compares the spectral and morphological data collected for the sample with source-specific data contained in the source library and uses a least-squares regression algorithm to identify the PM sources and their percent contribution to the mass of sample collected. This approach is similar to that employed using the chemical mass balance receptor model (CMB) except rather than using chemical fingerprints to identify contributing sources (Chow et al. [3]), use is made of spectral and morphological fingerprints. One major advantage of this fluorescence-based approach is it allows for the identification of source contributions in near-real time.

The existing MCI database had source signatures for mobile source emissions (gasoline and diesel, light-duty, heavy-duty, and motorcycle), industrial sources (smelting, foundries, etc.), vegetative burning, cooking, coal power plant emissions, geological material, oil burning, ship emissions, etc. To ensure we could characterize fugitive emissions from the power station, we sampled for coal dust, coal ash, and coal ash collected by the emissions control system. These samples were scanned and included in the source database.

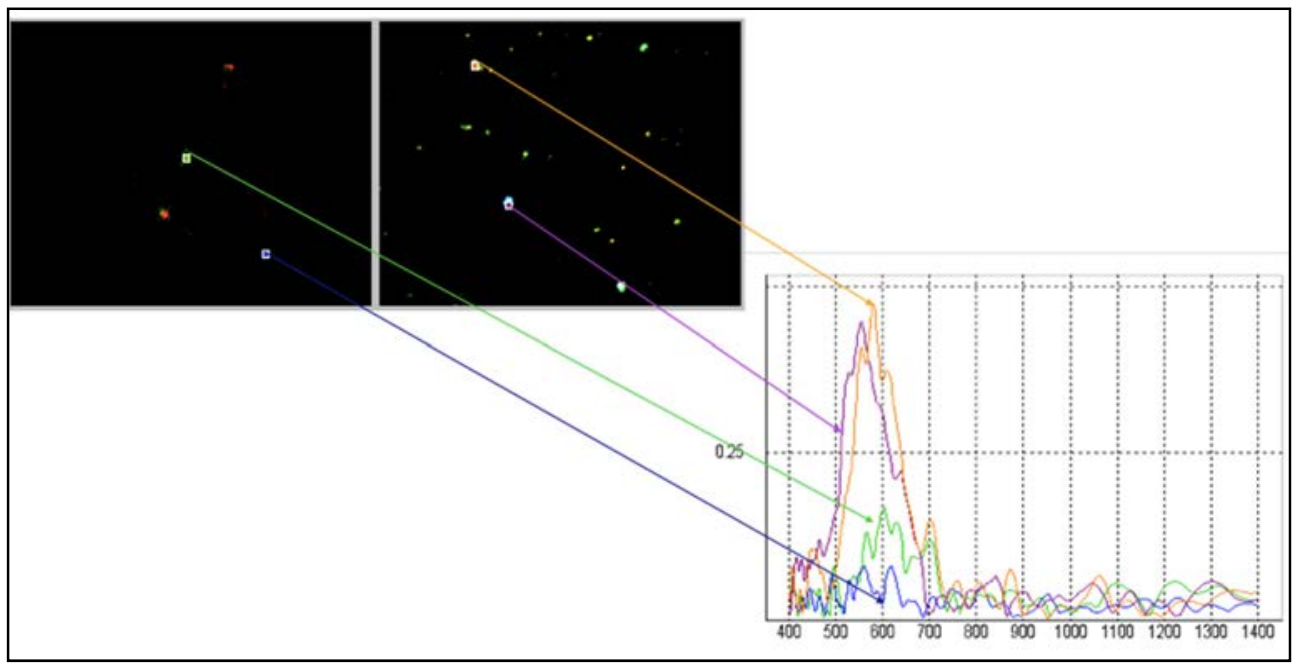

Figure 2: Example of pixel-by-pixel spectral information collected for individual particles. Observed spectra are then compared with previously developed source spectra to determine the source category of the collected ambient particle. 


\section{RESULTS}

The source apportionment results for all periods are presented in Figs 3 and 4 for Hephziba and Pardes-Channa, respectively. Table 1 summarizes the average source contributions for the periods shown in Figs 3 and 4 and for the timeframe when sampling overlapped at the two locations (September 13-October 3). The largest contribution at both locations was from mobile sources, with the next largest contribution coming from the power station. It is interesting to note that the results are quite similar for all measurement periods versus the overlap period. For the Hephziba monitoring site, located closest to the power plant and adjacent to a major highway, the mobile source contribution was $29.8 \%$ and the coal power plant contribution was $29.1 \%$. In addition, fugitive coal and coal residue was estimated to contribute $11.5 \%$ of the observed $\mathrm{PM}_{10}$. At the Pardes-Channa site, located further inland and in a more residential area, the mobile source contribution was $38.6 \%$, coal power plant emissions averaged $19.3 \%$, and the fugitive coal and coal residue contribution was $2.7 \%$. Based on these results, we see a significantly greater contribution from fugitive emissions at the Hephziba location (9.3\%) versus the Pardes-Channa location $(2.7 \%)$. This implies a greater impact of fugitive emissions from the power station at the nearby location and supports the need to control fugitive emissions from the plant.

Given the number of highways near the monitoring sites (Fig. 1), the large contribution from mobile sources at both locations is not surprising. However, what is unusual is the large contribution from the power station $(\sim 20 \%)$ at the more inland location. Clearly this has a major impact on ambient $\mathrm{PM}_{10}$ both locally and in the region and raises questions regarding the adequacy of the PM emissions control technology at the facility.

One other source to note is the port activities contribution. This is due to emissions from ships delivering coal to the power station. While this is relatively small, $0.4 \%$ and $1.4 \%$ at Pardes-Channa and Hephziba respectively, it demonstrates the ability of the MCI technique to differentiate between various sources, along with the showing the decreasing contribution from sources along the coast as one moves further inland.

Table 1: Average $\mathrm{PM}_{10}$ source contribution results for all measurement periods and the period when samples were simultaneously collected at both locations (September 13-October 3).

\begin{tabular}{|l|c|c|c|c|c|c|c|c|}
\hline & $\begin{array}{c}\text { Coal } \\
\text { Power } \\
\text { Plant \& } \\
\text { Industry }\end{array}$ & $\begin{array}{c}\text { Fujitive } \\
\text { Coal } \\
\text { Emissions }\end{array}$ & Industry & $\begin{array}{c}\text { Mobile } \\
\text { Sources }\end{array}$ & $\begin{array}{c}\text { Soil \& } \\
\text { Road Dust }\end{array}$ & $\begin{array}{c}\text { Biomass, } \\
\text { Cooking, } \\
\text { Garbage } \\
\text { Burning }\end{array}$ & $\begin{array}{c}\text { Port } \\
\text { Activities }\end{array}$ & $\begin{array}{c}\text { Unident. } \\
\text { Sources }\end{array}$ \\
\hline $\begin{array}{l}\text { Pardes- } \\
\text { Channa } \\
\text { (all) }\end{array}$ & 19.3 & 2.7 & 12.8 & 38.6 & 15.5 & 5.1 & 0.4 & 5.5 \\
\hline $\begin{array}{l}\text { Pardes- } \\
\text { Channa } \\
\text { (overlap) }\end{array}$ & 20.5 & 2.4 & 14.0 & 37.4 & 15.1 & 6.1 & 0.5 & 4.0 \\
\hline $\begin{array}{l}\text { Hephziba } \\
\text { (all) }\end{array}$ & 29.1 & 11.5 & 9.3 & 29.8 & 6.5 & 4.7 & 1.4 & 7.5 \\
\hline $\begin{array}{l}\text { Hephziba } \\
\text { (overlap) }\end{array}$ & 24.5 & 11.5 & 11.7 & 33.4 & 6.7 & 3.9 & 1.2 & 7.2 \\
\hline
\end{tabular}



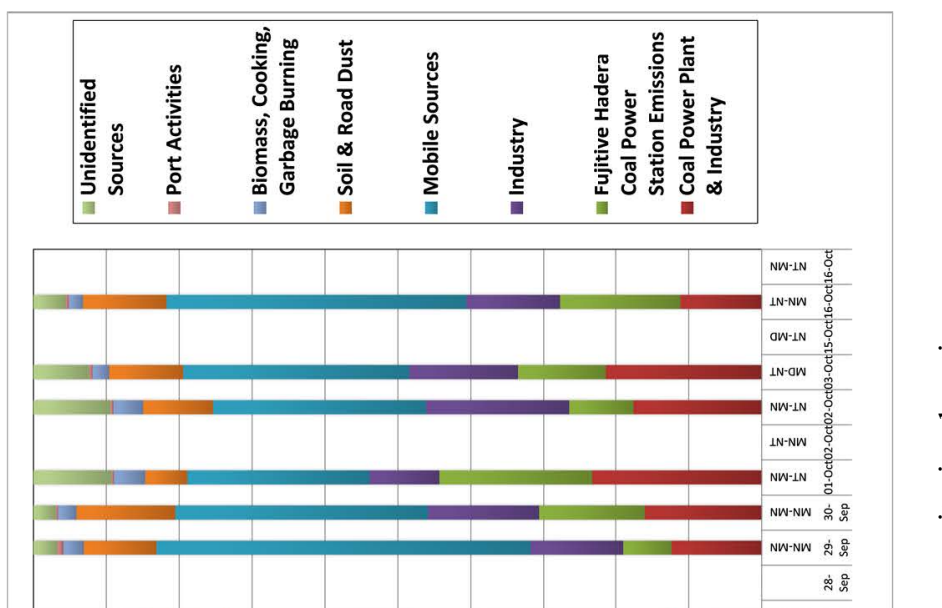


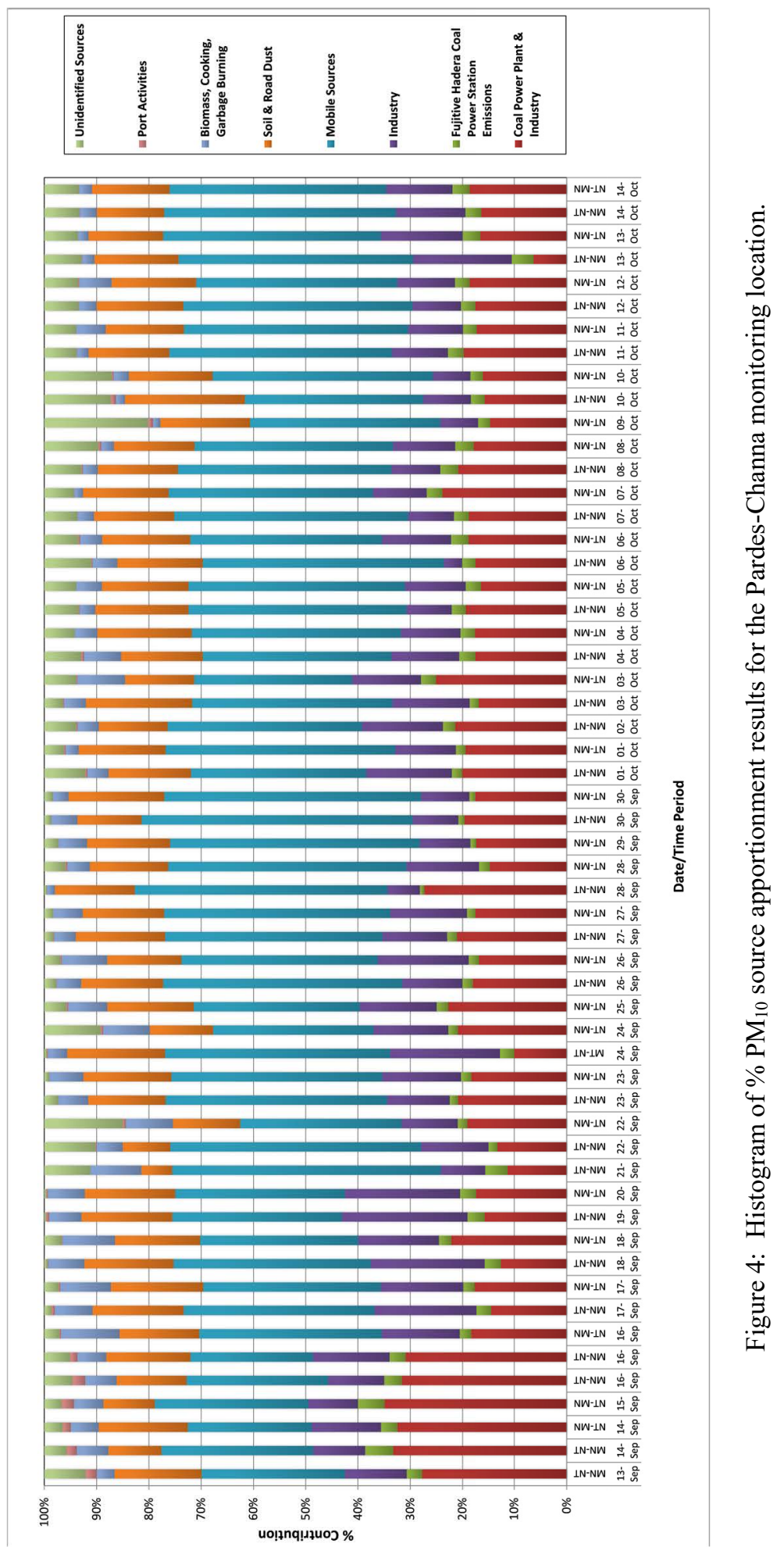




\section{SUMMARY AND CONCLUSIONS}

Following complaints of fugitive emissions from the Orot Rabin Power Station located in the area of Hadera, Israel, a source apportionment study was conducted to determine the sources contributing to the observed $\mathrm{PM}_{10}$. Two sites were chosen: Hephziba, located near the power station and the area from where the complaints were received, and Pardes-Channa, a location further inland. Samples were collected during the period of August 30 to October 16, 2017. Collection times varied from 12 to 24 hours, with the 12-hour samples ranging from midnight to noon and noon to midnight. The microscopic chemical imaging (MCI) technique was used to determine the source contributions.

Major findings included:

- Mobile sources and emissions from the coal power plant were the major contributors to $\mathrm{PM}_{10}$ at both locations.

- Industrial, soil and road dust, and biomass, cooking and garbage burning were also significant.

- Pardes-Channa (further downwind) was significantly impacted by emissions from the coal power plant ( $20 \%$ of primary emissions).

- The impact of fugitive emissions from the coal power plant were much greater at Hephziba.

- The impact of emissions from port activities were also much greater at Hephziba.

The findings support the complaints from Hephziba residents that they were impacted by fugitive emissions from the power station. In addition, the large contribution from the power station at the Pardes-Channa location raises questions regarding the adequacy of the PM emissions control technology at the power plant.

\section{ACKNOWLEDGEMENTS}

The authors would like to acknowledge the direct support received from CAEP SharonCarmel, Mr. Avi Mordechai and Mr. Doron Hornik for technical assistance and in-kind contributions from GVS for conducting this study. In addition, Dr. Gertler would like to thank the Lady Davis Fellowship Foundation at the Hebrew University and the Desert Research Institute for their support of his sabbatical.

\section{REFERENCES}

[1] Asaf, D. et al., Trans-boundary transport of ozone from the Eastern Mediterranean coast. Atmos. Environ., 45, pp. 5595-5601, 2011.

[2] Gertler, A.W., Moshe, D. \& Rudich, Y., Urban PM source apportionment mapping using microscopic chemical imaging. Sci. Tot. Environ., 488-489, pp. 456-460, 2014.

[3] Chow, J.C. et al., Evaluation of organic markers for chemical mass balance source apportionment at the Fresno Supersite. Atmos. Chem. Phys., 7(7), pp. 1741-2754, 2007. 